\title{
Erratum to: Effective endothelial cell and human pluripotent stem cell interactions generate functional insulin-producing beta cells
}

Dodanim Talavera-Adame ${ }^{1,2} \cdot$ Orison O. Woolcott $^{3} \cdot$ Joseph Ignatius-Irudayam $^{2}$. Vaithilingaraja Arumugaswami $^{1,2}$ • David H. Geller ${ }^{4}$ • Donald C. Dafoe ${ }^{1,2}$

Published online: 17 October 2016

(C) Springer-Verlag Berlin Heidelberg 2016

Erratum to: Diabetologia

DOI 10.1007/s00125-016-4078-1

The methods for cell transplantation in SCID mice should have read: 'Male SCID mice of the C.B-17/IcrHsd-Prkdc ${ }^{\text {scid }} L y s t$ tg-J strain (Envigo, Indianapolis, IN, USA) were divided into three groups, starting with 30 animals per group $(n=10$ mice per experiment).

The figure legend for Fig. 5 should have stated ' $n=3$ experiments'.

The online version of the original article can be found at http://dx.doi. org/10.1007/s00125-016-4078-1.

Dodanim Talavera-Adame

Talaverad@cshs.org

1 Comprehensive Transplant Center, Department of Surgery, Cedars-Sinai Medical Center, 8900 Beverly Boulevard, 251E, Los Angeles, CA 90048, USA

2 Board of Governors Regenerative Medicine Institute, Cedars-Sinai Medical Center, Los Angeles, CA, USA

3 Diabetes and Obesity Research Institute, Cedars-Sinai Medical Center, Los Angeles, CA, USA

4 Pediatric Endocrinology, Children's Hospital, Los Angeles, CA, USA 